Relations industrielles

Industrial Relations

\title{
Hommage à Claude D'Aoust, 1939-1993
}

\section{Gilles Trudeau, Guylaine Vallée et Diane Veilleux}

Volume 48, numéro 3, 1993

URI : https://id.erudit.org/iderudit/050870ar

DOI : https://doi.org/10.7202/050870ar

Aller au sommaire du numéro

Éditeur(s)

Département des relations industrielles de l'Université Laval

ISSN

0034-379X (imprimé)

1703-8138 (numérique)

Découvrir la revue

Citer ce document

Trudeau, G., Vallée, G. \& Veilleux, D. (1993). Hommage à Claude D'Aoust, 1939-1993. Relations industrielles / Industrial Relations, 48(3), 407-408. https://doi.org/10.7202/050870ar
Résumé de l'article

En considérant la seule offre de travail des hommes de la tranche d'âge 55-64 ans pour éliminer les effets de génération, les auteurs étudient sur une base économétrique les déterminants de la baisse du taux d'activité des travailleurs âgés au cours de la période 1967-1987. L'approche est réalisée en coupe et en série chronologiques et porte sur l'Allemagne, le Canada, la France, le Royaume- Uni et la Suède, cinq pays à niveaux de développement économique et social comparables.
Tous droits réservés @ Département des relations industrielles de l'Université Laval, 1993
Ce document est protégé par la loi sur le droit d'auteur. L'utilisation des services d'Érudit (y compris la reproduction) est assujettie à sa politique d'utilisation que vous pouvez consulter en ligne.

https://apropos.erudit.org/fr/usagers/politique-dutilisation/ 


\section{Hommage à Claude D'Aoust 1939-1993}

Le droit du travail québécois a perdu un de ses grands spécialistes avec le décès de notre collègue Claude D'Aoust. Qui parmi ceux et celles qui ont étudié ou qui pratiquent le droit du travail n'a pas lu, appris, analysé, cité ou critiqué un texte de Claude D'Aoust? Auteur prolifique, juriste vif et incisif, professeur d'une grande culture et très dévoué, Claude D'Aoust aura marqué à plus d'un égard tant ses étudiants que sa discipline de prédilection, le droit du travail.

C'est un chemin sinueux qui a fait de Claude D'Aoust le juriste émérite que nous connaissons. Il a d'abord complété une licence en droit à l'Université de Montréal pour s'inscrire ensuite au programme de maitrise en relations industrielles à la même université. C'est là qu'il a développé son intérêt pour le droit du travail mais aussi pour les relations industrielles en général. Il a particulièrement approfondi à cette époque la question de la syndicalisation des cadres. Après avoir complété sa maîtrise en relations industrielles, il s'est inscrit au programme de doctorat en sciences économiques de l'Université McGill. Ceci explique que plusieurs d'entre-nous avons connu Claude D'Aoust comme professeur d'économique à l'École de relations industrielles avant de découvrir en lui le juriste. Esprit indépendant, Claude D'Aoust a décidé de s'inscrire au Tableau de l'Ordre du Barreau du Québec il y a quelques années seulement. Fait rarissisme, il y fut admis sur la simple foi de ses réalisations, sans autre exigence ou formalité.

Claude D'Aoust a joint le corps professoral de l'École de relations industrielles en juin 1968. C'est littéralement à bout de bras qu'il y a développé l'enseignement et la recherche en droit du travail. Avant son arrivée, les cours de droit compris dans le programme de relations industrielles étaient donnés par des professeurs de la Faculté de droit. Comme professeur et chercheur, il a su intéresser plusieurs jeunes étudiants au droit du travail et leur communiquer sa passion pour cette discipline. À ces étudiants privilégiés, Claude D'Aoust a offert une disponibilité et une motivation hors du commun. Il leur a fait bénéficier de sa rigueur et de sa curiosité intellectuelle. Aujourd'hui, ces étudiants, que l'on retrouve tant dans le monde universitaire que dans la pratique privée, lui en sont grandement reconnaissants. 
Claude D'Aoust a marqué le milieu de la recherche universitaire en droit du travail. Certes, on retient d'abord la dimension utile des recherches qu'il a initiées, sur l'estoppel et les mesures disciplinaires, par exemple. Il convient cependant de noter le caractère fondateur des recherches qu'il a menées. Scruter la jurisprudence arbitrale, $y$ rechercher la règle de droit, en expliquer la formation et 1 'inscrire dans un cadre théorique constituait une démarche originale, novatrice, qui revenait à mettre en valeur l'originalité du droit du travail et le rôle particulier des tribunaux spécialisés dans ce domaine. Cette observation concernant l'objet de la recherche de Claude D'Aoust fait ressortir le paradoxe qu'il représentait comme juriste du travail. Claude D'Aoust n'hésitait pas à utiliser le droit civil, québécois et français. Il le connaissait de l'intérieur, mais aussi de l'extérieur à partir des comparaisons qu'il avait faites avec la common law et il en appliquait les concepts au droit du travail. Toutefois, paradoxalement, nous croyons que plusieurs de ses recherches contribuent à affirmer le caractère spécifique du droit du travail.

Nous, ses trois jeunes collègues de droit du travail de l'École de relations industrielles avons bénéficié de ses nombreux conseils, de sa grande disponibilité, de son immense culture juridique mais aussi de son indéfectible loyauté et amitié. Nous voulons rendre hommage à Claude D'Aoust au nom de tous ceux qui, en relations industrielles et en droit, ont eu l'immense privilège de bien le connaître.

Gilles Trudeau

Guylaine VALLÉE

Diane VeILleuX

Professeurs, École de relations industrielles, Université de Montréal 